\title{
О ВЛИЯНИИ ПОКАЗАТЕЛЕЙ ОБЕСПЕЧЕННОСТИ МЕДИЦИНСКОЙ СЛУЖБЫ ВНУТРЕННИХ ВОЙСК МИНИСТЕРСТВА ВНУТРЕННИХ ДЕЛ РОССИИ НА ЗАБОЛЕВАЕМОСТЬ ВОЕННОСЛУЖАЩИХ БОЛЕЗНЯМИ ОРГАНОВ ДЫХАНИЯ
}

\author{
(С Гладинец И.В. ${ }^{l}$, Будул Ю.И. , Каражелясков О.П. ${ }^{2}$, Бондаренко В.В. ${ }^{2}$, Ластовецкий А.Г. ${ }^{3}$, Гуревич К.Г. ${ }^{4}$
}

\author{
${ }^{1}$ Военно-медицинское управление Главного командования внутренних войск МВД России, Москва; \\ ${ }^{2}$ Медицинская служба Отдельной дивизии оперативного назначения внутренних войск МВД России, \\ Балашиха Московской области; ${ }^{3}$ Центральный научно-исследовательский институт организации \\ и информатизации здравоохранения, Москва; ${ }^{4}$ кафедра ЮНЕСКО «Здоровый образ жизни - \\ залог успешного развития» Московского государственного медико-стоматологического \\ университета им. А.И. Евдокимова, Москва \\ E-mail: olegkara@mail.ru
}

\begin{abstract}
Высокие уровни заболеваемости военнослужащих болезнями органов дыхания представляют серьезную проблему для медицинской службы внутренних войск МВД России. В ходе проведенного исследования авторами установлено, что на заболеваемость военнослужащих болезнями органов дыхания существенное влияние оказывает количество коек, развернутых в медицинском подразделении. Наибольшие значения показателя нуждаемости в коечном фонде имеют место с начала декабря по середину февраля. Развертывание нештатного изолятора перед эпидемически неблагоприятным периодом уменьшает заболеваемость внебольничными пневмониями в 2 раза, а соотношение зарегистрированных внебольничных пневмоний и острых респираторных инфекций достигает 1:18,5.
\end{abstract}

Ключевые слова: военнослужащий, изолятор, коечная емкость, внебольничная пневмония.

\begin{abstract}
EFFECT OF SUPPLY AVAILABILITY RATIO OF MEDICAL SERVICE IN THE RUSSIAN INTERNAL TROOPS OF THE MINISTRY FOR INTERNAL AFFAIRS ON RESPIRATORY MORBIDITY IN SERVICEMEN Gladinets I.V. ${ }^{1}$, Budul Yu.I. ${ }^{1}$, Karazhelyaskov O.P. ${ }^{2}$, Bondarenko V.V. ${ }^{2}$, Lastovetskiy A. G. ${ }^{3}$, Gurevich K.G. ${ }^{4}$

${ }^{1}$ Military Medical Directorate of High Command of Interior military Forces of the MIA of Russia, Moscow; ${ }^{2}$ Medical Service of Independent Operative Division of Interior military Forces of MIA of Russia, Balashikha, Moscow Region; ${ }^{3}$ Central Scientific Research Institute for Public Health, Moscow; ${ }^{4}$ UNESCO Department "Healthy Lifestyle the Key to Successful Development " of A.I. Evdokimov Moscow State University of Medicine and Dentistry, Moscow

High levels of respiratory morbidity among soldiers represent a serious challenge to the medical service of internal military forces of Ministry of Interior Affairs in Russia. In the course of the study the authors found out that the respiratory morbidity is significantly affected by bed availability in a medical division. The highest needs for beds arise from the beginning of December to mid-February. Deploying supernumerary insulator wards before the epidemiologically unfavorable period halves the incidence of community-acquired pneumonia, and the registered community-acquired pneumonia to acute respiratory infections ratio makes up to $1: 18.5$.
\end{abstract}

Keywords: soldier, insulator, hospital bed capacity, community-acquired pneumonia.

Снижение заболеваемости военнослужащих внутренних войск МВД России является одной из важнейших задач, влияющих на боевую готовность войск и национальную безопасность государства [5]. Специфика военной службы изначально предполагает риск здоровью, а иногда и жизни военнослужащего. На заболеваемость военнослужащих оказывают непосредственное влияние высокие психоэмоциональные нагрузки и условия службы [6]. Так, общая заболеваемость военнослужащих во внутренних войсках в 2009-2011 гг. составила 1105,7-1302,0\%о, при этом более $50 \%$ в ее структуре занимали болезни органов дыхания [7].

Одной из причин высокой заболеваемости болезнями органов дыхания является снижение общей резистентности организма, которая зависит от многих факторов, действующих в комплексе и часто являющихся взаимоотягчающими. Их длительное воздействие на военнослужащих может привести к развитию синдрома хронического эколого-профессионального перенапряжения [3]. Такой симптомокомплекс относится к донозологическим состояниям и расценивается как «предболезнь», или «предпатология» [4]. В период эпидемических вспышек доля таких военнослужащих может значительно увеличиваться, а число больных может многократно возрасти и вызвать значительное снижение боеготовности и боеспособности войск [1].

Контроль над распространением респираторных инфекций в коллективах, характеризующихся скученными условиями размещения и повышенными физическими нагрузками, представляет весьма сложную задачу. Предпринимаемые меры санитарно-гигиенического характера зачас- 
тую не дают ожидаемого эффекта [5]. Таким образом, одной из актуальных проблем, стоящих перед медицинской службой внутренних войск МВД России на современном этапе ее развития, является изучение медико-социальных проблем состояния и сохранения здоровья, в первую очередь - военнослужащих по призыву [4].

Цель исследования: оценить влияние обеспеченности медицинской службы войскового звена врачебным составом и количеством развернутых в медицинских подразделениях коек на заболеваемость военнослужащих болезнями органов дыхания.

\section{МАТЕРИАЛЫ И МЕТОДЫ ИССЛЕДОВАНИЯ}

Объект исследования - совокупность военнослужащих, проходящих военную службу по призыву и по контракту, обратившихся в медицинское подразделение по поводу заболевания, включенного в X класс Международной статистической классификации болезней и проблем, связанных со здоровьем, X пересмотра.

Оценка заболеваемости основывалась на анализе данных 78 отчетов «Заболеваемость, увольняемость, трудопотери, смертность военнослужащих, проходящих военную службу по призыву, и военнослужащих по контракту» в 2012-2014 гг. Проанализирована обеспеченность воинских частей соединений внутренних войск врачебным составом и койками для лечения больных в медицинских подразделениях. Для достижения поставленной цели был проведен ретроспективный анализ заболеваемости в отдельном соединении внутренних войск МВД России в 2009-2013 гг.

Математическая обработка проводилась при помощи стандартного пакета программ Statistica 7.0, для расчетов использовался коэффициент ранговой корреляции по Спирману, для определения средних величин использовались статистические критерии Стьюдента и Манна-Уинти, критерий статистической значимости выбран 0,05.

\section{РЕЗУЛЬТАТЫ ИССЛЕДОВАНИЯ И ИХ ОБСУЖДЕНИЕ}

На первом этапе проводимого исследования для оценки возможного влияния на заболеваемость количества коек, фактически развернутых в медицинских подразделениях воинских частей, мы сравнили заболеваемость и относительный показатель обеспеченности 1000 военнослужащих койками, развернутыми в медицинских подразделениях. Анализ проводился в 26 подразделениях внутренних войск МВД России среди военнослужащих по призыву и по контракту (табл. 1,2$)$.

Таблица 1

Зависимость между заболеваемостью военнослужащих по контракту и количеством развернутых коек в медицинском подразделении

\begin{tabular}{|l|c|c|c|}
\hline \multicolumn{1}{|c|}{ Класс болезней } & $\begin{array}{c}\text { Количество } \\
\text { наблюдений (n) }\end{array}$ & $\begin{array}{c}\text { Коэффициент корреляции по } \\
\text { Спирману (R) }\end{array}$ & $\begin{array}{c}\text { Уровень } \\
\text { достоверности (p) }\end{array}$ \\
\hline Общая заболеваемость & 26 & 0,212804 & 0,296605 \\
\hline $\begin{array}{l}\text { Класс 10. Болезни органов } \\
\text { дыхания }\end{array}$ & 26 & 0,131309 & 0,522566 \\
\hline $\begin{array}{l}\text { Острые респираторные } \\
\text { инфекции ВДП }\end{array}$ & 26 & 0,145041 & 0,479601 \\
\hline Бронхиты и бронхиолиты & 26 & 0,224328 & 0,270587 \\
\hline Пневмонии & 26 & 0,260647 & 0,312292 \\
\hline
\end{tabular}

Таблица 2

Зависимость между заболеваемостью военнослужащих по призыву и количеством развернутых коек в медицинском подразделении

\begin{tabular}{|l|c|c|c|}
\hline \multicolumn{1}{|c|}{ Класс болезней } & $\begin{array}{c}\text { Количество } \\
\text { наблюдений }(\mathrm{n})\end{array}$ & $\begin{array}{c}\text { Коэффициент корреляции по } \\
\text { Спирману (R) }\end{array}$ & $\begin{array}{c}\text { Уровень } \\
\text { достоверности (p) }\end{array}$ \\
\hline Общая заболеваемость & 23 & $-0,300272$ & 0,163886 \\
\hline $\begin{array}{l}\text { Класс 10. Болезни органов } \\
\text { дыхания }\end{array}$ & 23 & $-0,457447$ & 0,028184 \\
\hline $\begin{array}{l}\text { Острые респираторные } \\
\text { инфекции ВДП }\end{array}$ & 23 & $-0,603662$ & 0,002289 \\
\hline Бронхиты и бронхиолиты & 23 & $-0,722635$ & 0,000098 \\
\hline Пневмонии & 23 & $-0,432680$ & 0,039195 \\
\hline
\end{tabular}


Нами не выявлена достоверная связь между количеством коек и заболеваемостью военнослужащих по контракту. По всей видимости, это связано с тем, что военнослужащим по контракту при обращении за медицинской помощью по поводу заболеваний органов дыхания назначается амбулаторное лечение в домашних условиях, либо они направляются на стационарное лечение в военный госпиталь. Кроме этого, военнослужащие по контракту во время болезни в меньшей степени контактируют между собой, чем военнослужащие по призыву.

В ходе анализа не было выявлено достоверной зависимости между количеством коек и общей заболеваемостью военнослужащих по призыву. Однако существует достоверная $(\mathrm{p}<0,05)$ обратно пропорциональная зависимость количества коек с заболеваемостью болезнями органов дыхания, в частности, острыми респираторными инфекциями, бронхитами и пневмониями. Наиболее выражена достоверная зависимость с бронхитами $(\mathrm{R}=-0,72)$, а наименее - с пневмониями $(\mathrm{R}=-0,43)$. Таким образом, можно предположить, что чем выше значение показателя обеспеченности 1000 военнослужащих по призыву койками, тем ниже заболеваемость болезнями органов дыхания.

Вероятно, это связано с тем, что в осеннезимний период при массовом поступлении больных с заболеваниями органов дыхания почти всегда отмечается недостаточность коечного фонда, которая приводит либо к амбулаторному лечению заболевших в подразделении, что недопустимо, либо к потребности в развертывании нештатного изолятора. Естественно, что чем большее количество коек развернуто в медицинском подразделении, тем вероятность развертывания изолятора ниже, но определить потребность в развертывании изолятора иногда бывает затруднительно, так как не всегда имеется возможность предсказать дальнейшее развитие эпидемиологического процесса.

На втором этапе исследования был проведен анализ влияния обеспеченности медицинской службы кадровым составом на заболеваемость военнослужащих по призыву и по контракту.

Значимых связей между заболеваемостью и кадровым обеспечением медицинской службы, кроме заболеваний острыми бронхитами и бронхиолитами у военнослужащих по призыву, установлено не было. Это может свидетельствовать о том, что наиболее существенным ресурсным фактором, влияющим на заболеваемость болезнями $\mathrm{X}$ класса $\mathrm{y}$ военнослужащих по призыву, является коечный фонд, вследствие чего и встает вопрос о его оптимизации, т.е., другими словами, о необходимости оперативного развертывания нештатного изолятора во время осложнения эпидемической обстановки в воинских частях по болезням $\mathrm{X}$ класса, а также о необходимости создания в воинских частях резерва медицинского и вещевого имущества для его развертывания и наличии заблаговременно разработанных формализованных бланков учетной и отчетной документации.

Для оценки показателя нуждаемости в коечном фонде заболевших военнослужащих, нами проведен анализ зависимости количества госпитализаций от временного фактора из расчета на 1000 военнослужащих (рис. 1).

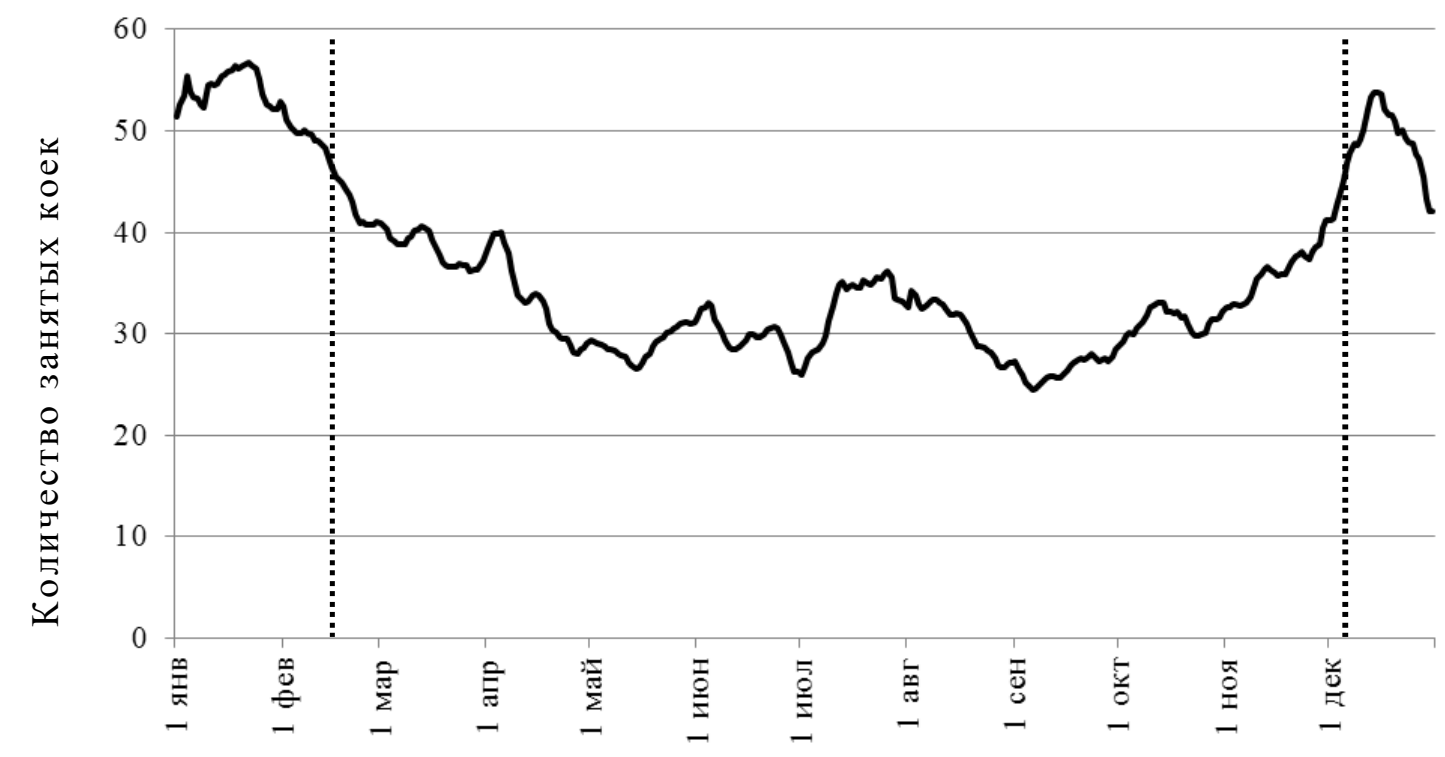

Рис. 1. Средняя занятость коек в медицинских подразделениях отдельного соединения ВВ МВД России в 2012-2014 гг., \%о 
На протяжении рассматриваемого в исследовании периода показатель нуждаемости в коечном фонде в медицинских подразделениях отдельного соединения в среднем составлял 25-35\%, однако в период роста заболеваемости болезнями органов дыхания значения показателя составляли 45-57\% (в отдельные годы значения данного показателя достигали 72\%о).

Установлено, что наибольшие значения показателя нуждаемости в коечном фонде имеют место с начала декабря по середину февраля. Также отмечается незначительное увеличение поступлений больных в летний период, что, скорее всего, связано с адаптацией и, соответственно, ростом заболеваемости военнослужащих весеннего призыва к условиям военной службы и новым климатическим условиям.

Таким образом, учитывая полученные данные, можно считать, что в межэпидемический период для лечения военнослужащих по призыву в медицинских подразделениях воинских частей достаточно 35 развернутых коек на 1000 военнослужащих, а в период роста заболеваемости болезнями органов дыхания имеется потребность в развертывании нештатных изоляторов с доведением количества коек до 75 на 1000 военнослужащих по призыву. Необходимо отметить, что для разных подразделений эти расчеты могут незначительно отличаться.

Предложенная организационная модель была апробирована в одной из воинских частей отдельного соединения в 2014-2015 гг. Проведя ретроспективный анализ заболеваемости болезнями органов дыхания, было определено, что ежегодно в зимний период на протяжении последних 5 лет ежемесячная заболеваемость военнослужащих воинской части внебольничной пневмонией составляла 15-22\%о, что было в 3,1 раза выше средних показателей во внутренних войсках МВД России.

До 2014 года в данной воинской части соотношение зарегистрированных внебольничных пневмоний и острых респираторных инфекций в среднем составляло 1:7. Указанный показатель характеризует качество проводимых в воинской части противоэпидемических мероприятий, и чем больше соотношение указанных нозологий, тем более качественно организованы и проводятся профилактические мероприятия [2]. Соотношение 1:7 свидетельствует о низкой эффективности профилактических мероприятий.

При заблаговременном развертывании нештатного изолятора в воинской части, в эпидемический период 2014-2015 гг. заболеваемость внебольничной пневмонией составила $11 \%$, а соотношение зарегистрированных внебольничных пневмоний и острых респираторных инфекций достигло 1:18,5.

Существенным плюсом разработанного алгоритма оптимизации медицинской помощи является снижение заболеваемости внебольничными пневмониями практически в 2 раза.

Таким образом, данные проведенного исследования показывают, что на заболеваемость болезнями органов дыхания существенное влияние оказывает количество коек, развернутых в медицинском подразделении. Развертывание нештатного изолятора перед эпидемически неблагоприятным периодом (из расчета 75 коек на 1000 военнослужащих), а не с началом развития эпидемиологического процесса, позволяет снизить вероятность развития вспышечной заболеваемости острыми респираторными заболеваниями, а также уменьшить заболеваемость внебольничными пневмониями среди военнослужащих по призыву практически в 2 раза.

\section{ЛИТЕРАТУРА}

1. Ершов Ф.И., Шульдяков А.А., Романцов М.Г., Рамазанова К.Х., Шульдякова О.Г. Совершенствование профилактики и лечения острых респираторных вирусных инфекций // Сарат. науч.-мед. журн. - 2013. - Т. 9, № 3. - С. 492-495.

2. Лучанинов Э.В., Туркутюков В.Б., Колосов В.П. Эпидемиологические особенности заболеваемости внебольничной пневмонией у военнослужащих // Бюллетень физиологии и патологии дыхания. 2007. - № 25. - C. 87-88.

3. Мануйлов В.М., Сидоров П.И., Казакевич Е.В. Психофизиологическая характеристика военнослужащих, проходящих службу по призыву, с заболеваниями органов дыхания // Воен.-мед. журн. - 2004. - Т. 325, № 8. - С. 27-33.

4. Мухаметжанов А.М., Смагулов Н.К., Жаутикова С.Б., Умер Ф.У., Жиенбаева К.М. Актуальные вопросы заболеваемости военнослужащих срочной службы // Совр. пробл. науки и образ. 2013. - № 3. - C. 131-137.

5. Редненко В.B. Клинико-эпидемиологические закономерности распространения Chlamydophila pneumoniae в воинских коллективах, создание оптимальных схем профилактики инфекции // Вестн. ВГМУ. - 2014. - Т. 13, № 1. - С. 77-83.

6. Рыбин В.В., Сабанин Ю.В., Ярославцев В.В., Каськов О.В., Рихтер В.В., Заволожин В.А., Калашникова А.С., Кузин С.Н. Об изменениях в структуре общей заболеваемости военнослужащих по призыву внутренних войск МВД России в период с 2006 по 2011 гг. // Инфекция и иммунитет. - 2012. - Т. 2, № 1-2. - С. 51.

7. Шиилин А.А. Основные направления совершенствования гигиенического воспитания военнослужащих в системе формирования здорового образа жизни // Вестн. ВМА. - 2015. - № 2. C. 184-188. 


\title{
ОРТОДОНТИЧЕСКАЯ ПОМОЩЬ КУРСАНТАМ ВЫСШИХ ВОЕННЫХ УЧЕБНЫХ УЧРЕЖДЕНИЙ: ПРОБЛЕМЫ И ПЕРСПЕКТИВЫ СОВЕРШЕНСТВОВАНИЯ
}

\author{
(С) Иорданишвили А.К. ${ }^{1}$, Солдатова Л.Н. ${ }^{2}$, Керимханов К.А. ${ }^{2}$ \\ ${ }^{1}$ Северо-Западный государственный медицинский университет имени И.И. Мечникова, \\ Санкт-Петербург; \\ 2 Лечебно-диагностический стоматологический центр «Альфа-Дент», Колпино, Санкт-Петербург \\ E-mail: $\underline{\text { slnzub@gmail.com }}$
}

\begin{abstract}
На основании стоматологического обследования 1746 лиц мужского пола в возрасте от 17 до 25 года изучена частота встречаемости основных зубочелюстных аномалий у курсантов высших военных учебных учреждений. Установлено, что различные зубочелюстные аномалии имели 44,2\% обследованных. В работе отмечено, что среди курсантов, страдающих зубочелюстными аномалиями (ЗЧА), на этапе ортодонтического лечения находились 215 (27,8\%) человек. Во всех случаях эти курсанты получали ортодонтическое лечение с применением эджуайс-техники (брекет-систем). Указывается, что у $6(0,7 \%)$ курсантов имеются ЗЧА третьей степени тяжести, что свидетельствует о дефектах военноврачебных комиссий. Важным аспектом военно-врачебной экспертизы будущих курсантов при оценке стоматологического здоровья должно быть выявление зубочелюстных аномалий, которые могут являться ограничением для поступления в высшие военные учебные учреждения. Сделан вывод о необходимости решения проблем при освидетельствовании молодых людей в связи с имеющимися у них ЗЧА. Данные вопросы требуют уточнения как в медицинском, так и юридическом плане.
\end{abstract}

Ключевые слова: зубочелюстные аномалии, курсанты, высшие военные учебные учреждения, лица молодого возраста, нуждаемость в ортодонтической помощи, ортодонтическое лечение.

\section{ORTHODONTIC HELP TO CADETS OF HIGHEST MILITARY EDUCATIONAL INSTITUTIONS: CHALLENGES AND FUTURE TRENDS Iordanishvili A.K. ${ }^{l}$, Soldatova L.N. ${ }^{2}$, Kerimkhanov K.A. ${ }^{2}$ \\ ${ }^{1}$ I.I. Mechnikov North-West Medical State University, St. Petersburg; \\ ${ }^{2}$ City Stomatologic Center "Alfa-dent", Kolpino, St. Petersburg}

The occurrence of the main dentoalveolar anomalies in cadets of highest military educational institutions is studied on the basis of dental inspection of 1,746 males aged from 17 to 25 . It was established that $44.2 \%$ of the examined students suffered from various dentoalveolar anomalies. In 215 cases the cadets received orthodontic treatment with the use of edgewisetechnique (bracket systems). The detection of $6(6.1 \%)$ cadets with severe dentoalveolar anomalies (third degree) testifies to imperfection in the work of military-medical commissions which must examine prospective conscripts and contract soldiers. An adequate military-medical examination of future cadets should include a dental health assessment, in particular dentoalveolar anomalies that can be a restriction for entering military educational institutions. We concluded that there is a need for solving the examination problems of young people having dentoalveolar anomalies. These questions require specification both in the medical and legal aspects.

Keywords: dentoalveolar anomalies, cadets, the highest military educational institutions, persons of young age, needs for the orthodontic help, orthodontic treatment.

В настоящее время в военно-медицинских организациях (ВМО) Вооруженных Сил Российской Федерации ортодонтическая помощь оказывается небольшому числу военнослужащих, в том числе курсантам высших военных учебных учреждений (ВВУУ), что обусловливается отсутствием в штате стоматологических подразделений $\mathrm{BMO}$ должностей врачей стоматологов-ортодонтов [4]. В то же время выявление зубочелюстных аномалий (ЗЧА) у молодых лиц, поступающих на военную службу по призыву или контракту, ВВУУ или образовательные учреждения среднего (полного) общего образования с дополнительными образовательными программами, имеющими целью военную подготовку несовершеннолетних граждан (суворовские военные, нахимовские военно-морские училища, кадетские (морские кадетские) корпуса и др.), является важной задачей военно-врачебной экспертизы в мирное время [1]. Это обусловливается тем, что граждане при первоначальной постановке на воинский учет, призыве на военную службу, поступлении на военную службу по контракту (призыву) часто признаются не годными к военной службе или направляются на лечение [3, 5]. Следует подчеркнуть, что после проведенного лечения лица освидетельствуются повторно, а при неудовлетворительном результате хирургического лечения, а также в сроки до шести месяцев после операций по поводу ЗЧА, они признаются временно негодными к военной службе $[6,7]$. 